\title{
Carotid Artery Stenting and Its Impact on Cognitive Function: A Prospective Observational Study
}

\author{
Avinash N Gupta, DNB ${ }^{1}$, Amit A Bhatti, DM, DNB ${ }^{1}$, Mudasir M Shah, DM, FINR ${ }^{1}$, \\ Niranjan P Mahajan, DM, DNB ${ }^{1}$, Divya K Sadana, $\mathrm{PhD}^{2}$, Vikram Huded, DM, FINR ${ }^{1}$ \\ ${ }^{1}$ Department of Neurology, Narayana Institute of Neurosciences, Bengaluru, India \\ ${ }^{2}$ Department of Neuropsychology, Narayana Institute of Neurosciences, Bengaluru, India
}

Purpose: Carotid artery stenting (CAS) has evolved as a first-line therapeutic option for carotid revascularization in indicated patients for stroke prevention, but there is still a lack of data on its effect on cognitive function (CF), especially among Indian patients. To determine the effect of CAS on CF and to study the immediate and delayed complications of CAS in Indian patients.

Materials and Methods: This was a prospective, observational, single-center study. CF was assessed using Addenbrooke's cognitive examination version III (ACE) before and 3 months after stenting. The demographic and clinical parameters were also assessed. A follow-up evaluation after 3 months was done to compare CF and to observe the occurrence of any complications.

Results: Out of 31 patients, 3 were lost to follow up. There were no immediate or delayed procedure-related complications. There was a statistically significant improvement in overall ACE score and memory before and after stenting. On subgroup analysis of those with and without strokes, there was a significant improvement in visuospatial function and mean ACE score. Those with left CAS had significant improvement in memory, visuospatial, language, and ACE scores than right CAS.

Conclusion: CAS was associated with significant improvement in CF in patients.

Key Words: Carotid stenosis; Cognitive dysfunction; Vascular dementia

\section{INTRODUCTION}

With the aging of the population, the prevalence of cognitive impairment is increasing and has become a focus of research.' Without substantial success in the treatment of degenerative diseases of cognition, the present strategy concerns the targeted and optimal treatment of modifiable risk factors that lead to vascular cognitive impairment (VCI). Carotid atherosclerosis and ca- rotid artery stenosis (CS) are leading causes of stroke in the elderly and thus may add to the burden of vascular dementia. ${ }^{2}$ Even when asymptomatic, it may contribute to cognitive decline, possibly due to silent embolization and chronic hypoperfusion, which may make it an independent risk factor for VCl. It follows that revascularization may halt or reverse cognitive dysfunction. However, revascularization procedures have also been implicated in a worsen-

\section{Correspondence to: Vikram Huded, DM, FINR Department of Neurology, $\mathrm{NH}$ Institute of Neurosciences, Narayana Health City, 258/A Bommasandra Industrial Area, Hosur Main Road, Bengaluru 560 099, Karnataka, India Tel: +91900002101 \\ Fax: +918027832648 \\ E-mail:drvikramhuded@gmail.com}

Received: February 3, 2020 Accepted: March 1, 2020
Copyright $\odot 2020$ Korean Society of Interventional Neuroradiology

This is an Open Access article distributed under the terms of the Creative Commons Attribution Non-Commercial License (http://creativecommons.org/licenses/by-nc/4.0) which permits unrestricted non-commercial use, distribution, and reproduction in any medium, provided the original work is properly cited.

pISSN 2093-9043 eISSN 2233-6273 
ing of cognitive function because of increased microemboli, temporary flow interruption from clamping (carotid endarterectomy) or balloon dilatation (carotid artery stenting [CAS]), or hyper-perfusion (post-procedure) related injury. 3,4 This interaction between CS, revascularization, and cognitive dysfunction remains poorly understood, with the published data showing mixed results. ${ }^{1,3-9}$ Hence, we conducted a study primarily to determine the effect of extracranial CAS on cognitive function and secondarily to study the immediate and delayed complications in Indian patients.

\section{MATERIALS AND METHODS}

This was a prospective observational study. Patients above 18 years of age who underwent stenting from June 2017 till November 2018 were included in the study. Patients with previously diagnosed dementia, less education, disabling strokes with a modified Rankin's score 3 or more, ${ }^{10}$ aphasia, psychiatric illness, drug or alcohol abuse, stenosis due to a non-atherosclerotic cause or calcified lesions, or severe hepatic or renal dysfunction were excluded.

All patients previously diagnosed to have CS with either magnetic resonance angiogram or computed tomography or Doppler ultrasound underwent digital subtraction angiography to determine the severity of stenosis based on the North American Symptomatic Carotid Endarterectomy Trial (NASCET)." Measurements of severity, length of the stenosis, and plaque characteristics were performed to select a properly-sized balloon and stent. Stenting was performed by a single neurointerventionist under local anesthesia and through a femoral approach. A distal protection device was used to prevent microembolisms during the procedure in all cases. Patients with symptomatic stenosis more than $50 \%$ or asymptomatic stenosis more than $70 \%$ as per NASCET criteria underwent stenting.

Cognitive function of the enrolled patients was assessed using Addenbrooke's cognitive examination version III (ACE) by a trained neuropsychologist before and 3 months after stenting. ${ }^{12}$ Apart from cognitive function, demographic and clinical data of the study patients were also analyzed. A follow-up evaluation after 3 months was done to compare the cognitive function, occurrence of stroke or transient ischemic attack (TIA), renal failure, or other vascular events like acute myocardial infarction (MI) or death (due to any cause). Carotid Doppler was also done during their visit to diagnose restenosis and measure flow across the stent. Informed consent from each participant and approval of the institutional ethics committee was taken for the study (IRB no. NHH/AECCL-2017-185).

\section{Statistical analysis}

Categorical data was represented in the form of frequencies and proportions. Continuous data were represented as mean and standard deviation. The chi-square test was used as a test of significance for qualitative data. The independent t-test or Mann-Whitney $U$ test was used as a test of significance to identify the mean difference between 2 quantitative variables and qualitative variables respectively.

Table 1. Demographic and clinical features of study patients $(\mathrm{n}=\mathbf{2 8})$

\begin{tabular}{|c|c|}
\hline Parameter & Value \\
\hline \multicolumn{2}{|l|}{ Demographic features } \\
\hline Age (y) & 60 \\
\hline Male & $25(89)$ \\
\hline Left handed & $3(11)$ \\
\hline \multicolumn{2}{|l|}{ Associated risk factors } \\
\hline Diabetes mellitus & $14(50)$ \\
\hline Hypertension & $24(86)$ \\
\hline Smoking & $9(32)$ \\
\hline $\begin{array}{l}\text { Hypercholesterolemia (total cholesterol } \\
\geq 200 \mathrm{mg} / \mathrm{dL} \text { or LDL-C } \geq 130 \mathrm{mg} / \mathrm{dL} \text { ) }\end{array}$ & $9(32)$ \\
\hline Coronary artery disease & $6(21)$ \\
\hline \multicolumn{2}{|l|}{ Presenting features } \\
\hline Retinal ischemia & $4(14)$ \\
\hline Transient ischemic attack & $15(54)$ \\
\hline Ischemic hemispheric stroke & $9(32)$ \\
\hline Asymptomatic & $0(0)$ \\
\hline \multicolumn{2}{|l|}{$\begin{array}{l}\text { Severity of stenosis on the symptomatic side } \\
\text { as per NASCET criteria }\end{array}$} \\
\hline $50-69 \%$ & $4(14)$ \\
\hline 70-79\% & $11(39)$ \\
\hline $80-89 \%$ & $5(18)$ \\
\hline$>90$ & $8(29)$ \\
\hline \multicolumn{2}{|l|}{ Side of stenting } \\
\hline Right & $11(39)$ \\
\hline Left & $17(61)$ \\
\hline
\end{tabular}

Values are presented as mean only or number (\%).

LDL-C, low-density lipoprotein cholesterol; NASCET, North American Symptomatic Carotid Endarterectomy Trial. 
The paired t-test and Wilcoxon signed-rank test were used for paired data such as before and after for quantitative and qualitative data respectively. A P-value $<0.05$ was considered to indicate statistical significance.

\section{RESULTS}

Thirty-one patients were enrolled during the study period out of which 3 were lost to follow up. The baseline clinical demographic features are as mentioned in Table 1. The pre- and post-stenting ACE scores and individual cognitive domain scores are compared in Table 2. Additionally, the cognitive function scores were compared between patients with stroke (established infarcts) and those with TIAs/retinal ischemic symptoms only, as shown in Table 3, and between left- and right-sided CAS procedures, as shown in Table 4.

There was no procedure-related complication or post-pro-

Table 2. Comparison between pre- and post-stenting cognitive functions

\begin{tabular}{llccc}
\hline Serial number & \multicolumn{1}{c}{ Cognitive function parameter } & Pre-stenting & Post-stenting & P-value \\
\hline 1 & Attention & $15.8 \pm 1.5$ & $16.1 \pm 1.6$ & 0.15 \\
2 & Memory & $17.8 \pm 4.7$ & $19.4 \pm 5.0$ & 0.02 \\
3 & Fluency & $8.4 \pm 2.6$ & $8.4 \pm 2.0$ & 1.00 \\
4 & Visuo-spatial & $12.9 \pm 3.3$ & $13.4 \pm 3.2$ & 0.15 \\
\hline 6 & Language & $22.4 \pm 2.8$ & $23.1 \pm 2.0$ & 0.11 \\
\hline
\end{tabular}

Values are presented as mean \pm standard deviation.

Table 3. Comparison of cognitive function among patients with and without stroke

\begin{tabular}{|c|c|c|c|c|c|c|}
\hline \multirow{2}{*}{$\begin{array}{l}\text { Serial } \\
\text { number }\end{array}$} & \multirow{2}{*}{$\begin{array}{l}\text { Cognitive function } \\
\text { parameter }\end{array}$} & \multicolumn{2}{|c|}{ Stroke } & \multicolumn{2}{|c|}{ Transient ischemic attacks/retinal ischemia } & \multirow{2}{*}{ P-value } \\
\hline & & Pre-procedure & Post-procedure & Pre-procedure & Post-procedure & \\
\hline 1 & Attention & $16.10 \pm 1.97$ & $16.30 \pm 2.11$ & $15.72 \pm 1.84$ & $16.17 \pm 1.76$ & 0.16 \\
\hline 2 & Memory & $18.20 \pm 2.49$ & $20.40 \pm 3.98$ & $17.56 \pm 5.59$ & $18.83 \pm 5.51$ & 0.08 \\
\hline 3 & Fluency & $8.40 \pm 2.72$ & $7.90 \pm 1.97$ & $8.44 \pm 2.55$ & $8.72 \pm 1.20$ & 0.52 \\
\hline 4 & Visuo-spatial & $12.70 \pm 3.59$ & $12.60 \pm 3.60$ & $13.00 \pm 3.20$ & $13.78 \pm 3.00$ & 0.04 \\
\hline 5 & Language & $22.00 \pm 2.31$ & $23.60 \pm 1.43$ & $22.67 \pm 3.09$ & $22.94 \pm 2.31$ & 0.64 \\
\hline 6 & $\begin{array}{l}\text { Addenbrooke's cognitive } \\
\text { examination score }\end{array}$ & $78.00 \pm 7.20$ & $81.20 \pm 9.94$ & $77.39 \pm 13.00$ & $80.56 \pm 10.98$ & 0.04 \\
\hline
\end{tabular}

Values are presented as mean \pm standard deviation.

Table 4. Comparison of cognitive function between side of stenting

\begin{tabular}{|c|c|c|c|c|c|c|}
\hline \multirow{2}{*}{$\begin{array}{l}\text { Serial } \\
\text { number }\end{array}$} & \multirow{2}{*}{$\begin{array}{l}\text { Cognitive function } \\
\text { parameter }\end{array}$} & \multicolumn{2}{|c|}{ Left } & \multicolumn{2}{|c|}{ Right } & \multirow{2}{*}{ P-value } \\
\hline & & Pre-procedure & Pre-procedure & Pre-procedure & Pre-procedure & \\
\hline 1 & Attention & $15.94 \pm 1.68$ & $15.94 \pm 1.71$ & $15.73 \pm 2.19$ & $16.64 \pm 2.06$ & 1.00 \\
\hline 2 & Memory & $16.59 \pm 5.21$ & $19.12 \pm 5.50$ & $19.64 \pm 3.04$ & $19.82 \pm 4.33$ & 0.04 \\
\hline 3 & Fluency & $8.12 \pm 2.47$ & $8.65 \pm 1.94$ & $8.91 \pm 2.73$ & $8.09 \pm 2.12$ & 0.26 \\
\hline 4 & Visuo-spatial & $12.35 \pm 3.53$ & $13.29 \pm 3.26$ & $13.73 \pm 2.80$ & $13.45 \pm 3.30$ & 0.02 \\
\hline 5 & Language & $21.88 \pm 2.80$ & $23.12 \pm 2.42$ & $23.27 \pm 2.72$ & $23.27 \pm 1.35$ & 0.036 \\
\hline 6 & $\begin{array}{l}\text { Addenbrooke's cognitive } \\
\text { examination score }\end{array}$ & $75.24 \pm 12.00$ & $80.35 \pm 11.29$ & $81.27 \pm 8.90$ & $81.45 \pm 9.46$ & 0.002 \\
\hline
\end{tabular}

Values are presented as mean \pm standard deviation. 
cedure event (stroke, TIA, myocardial infarction, or death). On follow up comparison between pre- and post-stenting cognition of the patients, there was a statistically significant improvement in mean ACE score $(P<0.008)$ and memory $(P<0.02)$. Between patients with and without stroke, there was a significant improvement in visuospatial function and mean ACE score $(P<0.04$, each). Among patients undergoing left-sided stenting, memory, visuospatial, language, and ACE scores were found to have significant improvement (with P-values less than $0.04,0.02,0.036$, and 0.002 , respectively) as compared to those who underwent right-sided CAS.

\section{DISCUSSION}

Determination of symptomatic or asymptomatic status of a CS does not take cognitive function of the patient into account. Though it is well known that stroke is a cause of dementia, carotid stenosis itself is yet not recognized as an independent risk factor for a cognitive decline., ${ }^{4,13}$ The objective of our study was to determine this relationship between the effects of CAS on CF. We had used ACE score as it is widely applied in clinics as a battery for evaluation of cognitive function. In our study, we found that there was a significant improvement in the overall ACE score and memory after CAS. We also found significant improvement in memory, visuospatial, language, and overall ACE scores of patients who underwent left carotid stenting, which is expected as the left hemisphere is dominant in the majority of cases. A similar differential improvement between right- and left-sided stenting was observed in 1 study by Ishihara et al. ${ }^{14}$ The possible mechanisms may be related to restoration of flow to the chronically hypoperfused brain and prevention of further strokes by preventing the progression of local atherosclerotic lesions. ${ }^{3,48}$ Some of the studies have also shown that stenting itself may be associated with deterioration of cognitive function, ${ }^{15}$ or associated with mixed results. ${ }^{4}$ However, this is contrary to our study findings. One large prospective study from China also supports the findings of our study in which they found significant and sustained improvement in cognition after carotid stenting. ${ }^{9}$ The absence of any major complication in our study may have contributed to better functional cognitive outcomes. The reported rate of complications (stroke, TIA and MI) during stenting in various studies has been $6 \%$ to $9 \%$ for symptomatic and $2 \%$ to $4 \%$ for asymptomatic patients. ${ }^{16-18}$ The data on the rate of periproce- dural complications amongst Indian patients during CAS is scarce. One study by Gupta et al. ${ }^{19}$ reported a periprocedural mortality rate of around $8.1 \%$ and minor stroke of about $4.1 \%$. Another reason for the positive outcome could be the uniform procedure, namely, the use of a distal protection device and a single operator in all cases.

This was an observational study with a small sample size; hence, the results should be confirmed in a randomized controlled trial. Although the ACE is a validated tool for cognitive assessment, it may not reflect the overall cognitive function of patients. Confounding factors due to the practice effect may not be eliminated because of a lack of a control group. In addition, the study of regional blood flow and the effect of infarct location, as far as the eloquent nature of the cortex is concerned, must also be considered before cognitive decline is attributed to a carotid lesion. The risk factors of CS also contribute to vascular dementia., ${ }^{1,3}$ Hence, the real contribution of CS in cognitive decline independent of the other risk factors must also be studied. Further large scale studies with standardized cognitive assessment are required for a better understanding of the complex nature of the interaction between carotid atherosclerosis and cognition.

\section{CONCLUSION}

Carotid atherosclerosis may contribute to the burden of cognitive impairment; stenting in indicated patients may help in prevention of cognitive decline.

\section{Acknowledgments}

We thank Ms Delitia Manuel for her valuable help with the statistical analysis of the study.

\section{Fund}

None.

\section{Ethics Statement}

Ethics approval was obtained from the NH Institute of Neurosciences Institutional Review Board (IRB no. NHH/AECCL-2017-185).

\section{Conflicts of Interest}

The authors have no conflicts to disclose. 


\section{Author Contribution}

Concepts and design: ANG and VH. Definition of intellectual content: $A A B$ and NPM. Literature search: ANG and MMS. Clinical studies and data collection: ANG, AAB, and DKS. Data acquisition and analysis: ANG, NPM, and DKS. Manuscript preparation: ANG and MMS. Critical revision of the article: $A A B$ and $V H$. Overall responsibility: $V H$. Obtained funding: none.

\section{ORCID}

Avinash N Gupta: https://orcid.org/0000-0002-7300-4745

Amit A Bhatti: https://orcid.org/0000-0001-6607-457X

Mudasir M Shah: https://orcid.org/0000-0002-6752-594X

Niranjan P Mahajan: https://orcid.org/0000-0002-2432-4507

Divya K Sadana: https://orcid.org/0000-0003-1063-7024

Vikram Huded: https://orcid.org/0000-0001-5018-8003

\section{REFERENCES}

1. Dutra AP. Cognitive function and carotid stenosis: review of the literature. Dement Neuropsychol 2012;6:127-130

2. Ferri CP, Schoenborn C, Kalra L, Acosta D, Guerra M, Huang Y, et al. Prevalence of stroke and related burden among older people living in Latin America, India and China. J Neurol Neurosurg Psychiatry 2011;82:1074-1082

3. Sztriha LK, Nemeth D, Sefcsik T, Vecsei L. Carotid stenosis and the cognitive function. J Neurol Sci 2009;283:36-40

4. Plessers M, Van Herzeele I, Vermassen F, Vingerhoets G. Neurocognitive functioning after carotid revascularization: a systematic review. Cerebrovasc Dis Extra 2014;4:132-148

5. Zhou W, Hitchner E, Gillis K, Sun L, Floyd R, Lane B, et al. Prospective neurocognitive evaluation of patients undergoing carotid interventions. J Vasc Surg 2012;56:1571-1578

6. Grunwald IQ, Supprian T, Politi M, Struffert T, Falkai P, Krick C, et al. Cognitive changes after carotid artery stenting. Neuroradiology 2006:48:319-323

7. Turk AS, Chaudry I, Haughton VM, Hermann BP, Rowley HA, Pulfer K, et al. Effect of carotid artery stenting on cognitive function in patients with carotid artery stenosis: preliminary results. AJNR Am J Neuroradiol 2008;29:265-268

8. Lehrner J, Willfort A, Mlekusch I, Guttmann G, Minar E, Ahmadi $\mathrm{R}$, et al. Neuropsychological outcome 6 months after unilateral carotid stenting. J Clin Exp Neuropsychol 2005;27:859-866

9. Xia ZY, Sun QJ, Yang H, Zhang MX, Ban R, Xu GL, et al. Effect of carotid artery stenting on cognitive function in patients with internal carotid artery stenosis and cerebral lacunar infarction: a 3-year follow-up study in China. PLoS One 2015;10:e0129917

10. Saver JL, Filip B, Hamilton S, Yanes A, Craig S, Cho M, et al.; FASTMAG Investigators and Coordinators. Improving the reliability of stroke disability grading in clinical trials and clinical practice: the Rankin Focused Assessment (RFA). Stroke 2010;41:992-995

11. Ferguson GG, Eliasziw M, Barr HW, Clagett GP, Barnes RW, Wallace MC, et al. The North American Symptomatic Carotid Endarterectomy Trial: surgical results in 1415 patients. Stroke 1999;30:1751-1758

12. Bruno D, Schurmann Vignaga S. Addenbrooke's cognitive examination III in the diagnosis of dementia: a critical review. Neuropsychiatr Dis Treat 2019;15:441-447

13. Korczyn AD, Vakhapova V. The prevention of the dementia epidemic. J Neurol Sci 2007;257:2-4

14. Ishihara H, Oka F, Shirao S, Kato S, Sadahiro H, Osaki M, et al. Cognitive outcome differences on the side of carotid artery stenting. J Vasc Surg 2013;57:125-130

15. Gaudet JG, Meyers PM, McKinsey JF, Lavine SD, Gray W, Mitchell $E$, et al. Incidence of moderate to severe cognitive dysfunction in patients treated with carotid artery stenting. Neurosurgery 2009;65:325-329; discussion 329-330

16. SPACE Collaborative Group, Ringleb PA, Allenberg J, Brückmann $\mathrm{H}$, Eckstein $\mathrm{HH}$, Fraedrich $\mathrm{G}$, et al. 30 day results from the SPACE trial of stent-protected angioplasty versus carotid endarterectomy in symptomatic patients: a randomised non-inferiority trial. Lancet 2006;368:1239-1247

17. Mas JL, Chatellier G, Beyssen B, Branchereau A, Moulin T, Becquemin JP, et al.; EVA-3S Investigators. Endarterectomy versus stenting in patients with symptomatic severe carotid stenosis. N Engl J Med 2006;355:1660-1671

18. International Carotid Stenting Study investigators, Ederle J, Dobson J, Featherstone RL, Bonati LH, van der Worp HB, et al. Carotid artery stenting compared with endarterectomy in patients with symptomatic carotid stenosis (International Carotid Stenting Study): an interim analysis of a randomised controlled trial. Lancet 2010;375:985-997

19. Gupta AK, Purkayastha S, Kapilamoorthy TR, Nair MD, Krishnamoorthy T, Rupa S, et al. Carotid artery stenting: results and long-term follow-up. Neurol India 2006;54:68-72 